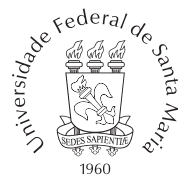

DOI: http://dx.doi.org/10.5902/2236672536923

Recebido em: 01/03/2019. Aprovado em: 30/07/2019.

\title{
A TRAVESTI, A ONÇA PINTADA E A SUCURI: REFLEXÕES SOBRE REGIME DE VISIBILIDADE NO PANTANAL, MS.
}

THE TRANSVESTITE, THE JAGUAR AND THE SUCURI: REFLECTIONS ON THE REGIME OF VISIBILITY IN THE PANTANAL, MS

LE TRAVESTI, LE JAGUAR ET LA SUCURI: DES RÉFLEXIONS SUR LA POLITIQUE DE LA VISIBILITÉ AU PANTANAL, MS.

EL TRAVESTI, EL JAGUAR Y EL SUCURI: REFLEXIONES SOBRE EL RÉGIMENDE VISIBILIDAD ENEL PANTANAL, MS.

Tiago Duque*

iD $h t t p s: / / o r c i d . o r g / 0000-0003-1831-0915$

\begin{abstract}
RESUMO: Este artigo discute regime de visibilidade a partir da experiência de uma travesti que vive na cidade de Corumbá, em Mato Grosso do Sul. A cidade fica no Pantanal e faz fronteira com a Bolívia. Por meio da etnografia, percebe-se que a gestão da visibilidade em termos de gênero e sexualidade não deixa passar incólume os códigos e valores da realidade pantaneira, como, por exemplo, a onça pintada e a sucuri, animais espetacularizados pela mídia e hipervalorizados pelos turistas. Esses animais são compreendidos na análise como agindo de forma cultural-natural. Através de um referencial teórico multidisciplinar, que perpassa entre os estudos de gênero e aos estudos fronteiriços e pantaneiros, a onça pintada e a sucuri são problematizadas como sendo performáticas e protéticas. Os relatos de campo contam sobre a incorporação protética e a performance da travesti com esses animais em eventos públicos na cidade, como o Amistoso da Diversidade e o Carnaval. Conclui-se que, considerando a realidade fronteiriça e pantaneira, o regime de visibilidade estrategicamente manipulado pela travesti e por outros efeminados e efeminadas da cidade, colocam essas pessoas em um
\end{abstract}

\footnotetext{
* Doutor em Ciências Sociais pela Universidade Estadual de Campinas (Unicamp), professor do Programa de Pós-Graduação em Antropologia da Universidade Federal do Mato Grosso do Sul (UFMS), Campo Grande, MS, Brasil; E-mail: duque_hua@yahoo.com.br
} 
lugar de reconhecimento social diante de diferentes grupos da cidade, além de produzir uma diferenciação valorativa da identidade nacional diante de um "outro" desvalorizado.

Pantanal.

Palavras Chaves: prótese; performance; travesti; fronteira;

ABSTRACT: This article discusses a regime of visibility based on the experience of a transvestite who lives in the city of Corumbá, MS. The city is located in the Pantanal and borders Bolivia. Through ethnography, it is perceived that the management of visibility in terms of gender and sexuality does not let go unharmed the codes and values of the Pantanal reality, such as, for example, the jaguar and the sucuri, animals spectacularized by the media and hyper Valued by tourists. These animals are understood in the analysis as acting in a cultural-natural way. Through a multidisciplinary theoretical framework, ranging from gender studies to border and pantaneiros, the jaguar and the sucuri are problematized as being performatic and prosthetic. The field reports count on the incorporation and performance of the transvestite with these animals in public events in the city, such as the friendly diversity and carnival. It is concluded that, considering the border and Pantanal reality, the regime of visibility strategically manipulated by the transvestite and by other effeminates/those of the city, put them in a place of social recognition in the face of different groups of City, in addition to producing a valuative differentiation of national identity in the face of another devalued.

Keywords: prosthesis; performance; transvestite; border; Pantanal.

RÉSUMÉ: Cet article discute sur la politique de la visibilité ayant pour base l'expérience d'un travesti qui habite dans la ville de Corumbá, MS. Cette ville se situe dans la région du Pantanal et elle divise la frontière avec la Bolivie. Par le biais de l'ethnographie, on perçoit que la gestion de la visibilité en termes de genre et sexualité ne laisse pas passer intact les codes et valeurs de la réalité du Pantanal, par exemple, le jaguar et la sucuri, qui sont des animaux spectaculaires sur le plan médiatique et sont aussi hyper valorisés par les touristes. Ces animaux sont problématisés à partir de l'analyse comme des acteurs qui agissent d'une manière culturelle et naturelle. Par moyen d'une théorie référentielle multidisciplinaire, qui a pour point de départ des études sur le genre jusqu'aux frontaliers et aux habitants du Pantanal, le jaguar et la sucuri sont mis en évidences comme étant des performeurs prothétiques. Les témoignages 
obtenus du champ de recherche parlent sur l'incorporation et la performances d'un travesti avec les deux animaux cités ci-dessus dans des événements publiques de la ville. Comme "amistoso da diversidade" et le carnaval. Nous concluons que, en considérant la réalité frontalière e du Pantanal, la politique de la visibilité est manipulée tactiquement par le travesti et par les autres/les efféminés de la ville, en les mettant dans une place de reconnaissance sociale par devant les autres groupes différents et en plus de ça ils produisent aussi une différenciation de la valeur de l'identité nationale devant une autre dévalorisée.

Mots Clés: prothèse; performance; travesti; frontière; Pantanal.

RESUMEN: Este artículo aborda un régimen de visibilidad basado en la experiencia de una travesti que vive en la ciudad de Corumbá, MS. La ciudad se encuentra en el Pantanal y limita con Bolivia. A través de la etnografía, se percibe que la gestión de la visibilidad en términos de género y sexualidad no deja ir ilesos los códigos y valores de la realidad del Pantanal, tales como, por ejemplo, el jaguar y el sucuri, animales espectacularizados por los medios de comunicación y hiper valorado por los turistas. Estos animales se entienden en el análisis como actuando de una manera cultural-natural. A través de un marco teórico multidisciplinar, que abarca desde estudios de género hasta frontera y pantaneiros, el jaguar y el Sucuri se problematizan como performáticos y protésicos. Los informes de campo cuentan con la incorporación y el rendimiento de la travesti con estos animales en eventos públicos en la ciudad, como la diversidad amistosa y el carnaval. Se concluye que, considerando la frontera y la realidad del Pantanal, el régimen de visibilidad manipulado estratégicamente por la travesti y por otros afeminados/das de la ciudad, los puso en un lugar de reconocimiento social frente a diferentes grupos de Ciudad, además de producir una diferenciación valuativa de la identidad nacional frente a un devaluado "Otro".

Palabras clave: prótesis; performance; travesti; frontera; Pantanal.

\section{INTRODUÇÃO}

"Somos parte da natureza. E, do mesmo modo, somos parte das palavras também”. Manoel de Barros (1986) 
O objetivo deste artigo é discutir parte dos resultados da pesquisa "Gênero, sexualidade e diferenças: normas e convenções sociais na fronteira Brasil-Bolívia", iniciada em 2014. O trabalho de campo, considerando a pesquisa integralmente, envolve etnografia off-line e on-line: atividades em espaços públicos e privados da cidade de Corumbá (festas, escolas, desfiles cívicos e de beleza, eventos esportivos, religiosos e político-culturais) e ambientes de sociabilidade na internet (sala bate papo, aplicativos de celular, sites e perfis nas redes sociais). Parte dos resultados, alguns envolvendo a participação de outros pesquisadores e pesquisadoras, foram publicados em artigos anteriores (Passamani, Duque, 2017; Duque, 2018a; Duque 2018b; Mota, Duque, 2018; Silveira, Duque; 2018).

Mais especificamente, o contexto deste estudo é a cidade de Corumbá, no estado de Mato Grosso do Sul. Considerada como a capital do Pantanal, a cidade possui uma estimativa de 108.656 habitantes, segundo dados do Instituto Brasileiro de Geografia e Estatística (IBGE, 2015) $)^{1}$, e está na região de outras três cidades, sendo Ladário a brasileira, e as de Puerto Quijaro e Puerto Soárez, as bolivianas.

Com esse enfoque não pretendo reduzir a complexidade cultural da região fronteiriça, antes, fazer um recorte preciso em relação à parte da vida na referida cidade, uma vez que

a multiplicidade e riqueza do cenário sociocultural pantaneiro é tal que abriga povos com línguas diferentes, com histórias e atividades econômicas próprios, com costumes particulares que os distinguem no contexto da planície (Banducci Junior, 2012, p. 21).

Segundo o Mapa de Biomas do Brasil (IBGE, 2004), o Bioma Pantanal é a maior planície de inundação contínua do Planeta Terra, o que faz com que parte de sua fauna se refugie nas áreas mais altas, como, por exemplo, onde está a cidade. Essa movimentação dos animais tem relação direta com parte dos dados que serão analisados aqui. Mas essa reflexão não se trata de uma análise do Pantanal, seus

1 Disponível em: http://www.cidades.ibge.gov.br/xtras/temas.php?lang=\&codmun=500320\&idtema $=130 \&$ search $=$ mato-grosso-do-sul|corumba|estimativa-da-populacao-2015-. Acesso em: 05 nov. 2018. 
significados e fronteiras, antes, no Pantanal. No entanto, conforme Alexandre Aldo Neves e Cláudio Benito O. Ferraz (2012), entendo que, atualmente, a ideia de Pantanal

é o resultado de uma diversidade de discursos, enunciado e construções imagéticas que, ao longo da processualidade das relações sócio-econômicas da modernidade ocidental, que nesse lugar se produziu, desdobrou no conjunto de elementos, alguns obscuros e silenciados, outros estereotipados e massificados, que atualmente se interacionam e se tencionam na configuração desse arranjo territorial, o qual se manifesta numa paisagem para além do conjunto natural nele presente. (Idem, p. 185).

Assim, mais precisamente a partir dos dados de campo, interesso-me pelas experiências de efeminados e efeminadas, isto é, as de gays e travestis, considerando que, nesta região, esta categoria abarca tanto um como o outro grupo identitário, sendo eles e elas uma categoria êmica, isto é, utilizada pelos interlocutores da pesquisa. Ela aparece quando é atribuída ou adotada por homens gays efeminados que buscam ou mantém relacionamento afetivo-sexual com outros homens, ou por travestis que foram assignadas como homens ao nascer, mas que, ao longo de sua vida, têm se identificado com o gênero feminino. Seja um ou outro, os usos são dinâmicos e carregam em si certa fluidez em termos de valoração, sendo mantidos em alguns contextos de desprestígio social e em outros de valorização dos sujeitos. São usos, portanto, que constituem regimes de visibilidade em relação a gênero e sexualidade dissidentes.

Assim, ouvi de um jovem gay em um contexto do trabalho de campo que "é mais fácil para efeminados ganharem o concurso [de transformismo] porque eles já têm um andar para a passarela". Os gêneros masculino e feminino aparecem misturados em muitos usos dessa categoria. Em outro contexto, de um jovem não gay e não efeminado, mas que matinha relacionamento afetivo-sexual com outros jovens gays, escutei que eu não deveria andar pela cidade acompanhado de efeminadas e/ou efeminados, pois isso "pegaria mal", isto é, não transmitiria uma boa imagem da minha pessoa aos munícipes. Nesse caso, ele se referia às companhias das travestis. A 
fronteira do masculino e feminino, assim como da identidade de gay e travestis no contexto da pesquisa, são bastante flexíveis, porque presenciei interlocutoras autodeclaradas travestis apresentando-se também publicamente como gays em situações diversas. Aqui, esse tipo de diferenciação identitária não será objeto de análise, no entanto, parece-me bastante adequado compreender efeminadas/os como a categoria êmica que melhor classifica a diversidade de interlocutoras/es desse estudo.

Nesse caso, a masculinidade, portanto, o efeminamento, de parte dos interlocutores é entendida aqui a partir de certo descumprimento performativo, isto é, uma dissidência da matriz de inteligibilidade de gênero apresentada por Butler (2003): "sexo" masculino = gênero masculino = desejo pelo "sexo oposto" (ou, em se tratando de feminilidade, "sexo" feminino = gênero feminino = desejo pelo "sexo oposto"). Evidentemente que, no caso em questão, o não cumprimento dessa matriz também em relação ao desejo, e não apenas ao gênero masculino, isto é, o desejo por alguém que não é do "sexo oposto", escapa a certos controles disciplinares dos prazeres, produzindo também uma espécie de sexualidade disparatada (Foucault, 2007).

Entendo regime de visibilidade nos termos de Richard Miskolci, isto é, como aquilo que "traduz uma relação de poder sofisticada, pois não se baseia em proibições diretas, antes em formas indiretas, mas altamente eficientes, de gestão do que é visível e aceitável na vida cotidiana" (2014, p.62). Essas relações de poder, em termos identitários, alocam, por vezes, como será discutido, o "outro lado" da fronteira como sendo depreciativo. Assim, no que se refere a esses regimes e aos efeminados e efeminadas, como aponta Guilherme Rodrigues Passamani (2018), é preciso reconhecer também que a noção de regime de visibilidade implica compreender que existe uma série de códigos e valores que se impõem como uma espécie de gramática às pessoas envolvidas, nas maneiras como elas podem parecer visíveis em relação à orientação sexual e à identidade de gênero. Dito de outro modo, negociar com estes regimes de visibilidade exige a produção de uma série de estratégias de gestão desta visibilidade. As estratégias, nesse caso, partem de um contexto fronteiriço: 
A fronteira em seu sentido mais comum está ligada ao preconceito por sua condução de margem, portanto, marginal a uma noção, decorrentes de questões históricas e políticas. É um local no qual se pode assimilar a negatividade, atribuída por diversos fatores como o ilícito, a clandestinidade, a miscigenação, entre outros (Oliveira; Campos, 2012, p. 17).

Por isso, a gestão desta visibilidade em termos de gênero e sexualidade não deixa passar incólume os códigos e valores da realidade pantaneira, em especial, parte da fauna hipervalorizada da região conforme discutirei. Isso será analisado a partir de uma das interlocutoras do trabalho de campo, a travesti Vânia ${ }^{2}$, de aproximadamente quarenta e cinco anos, negra, mas não retinta, moradora de uma região que não é nem a mais e nem a menos valorizada da cidade. Ela é uma pessoa bastante conhecida no contexto etnográfico. $\mathrm{O}$ meu primeiro contato com Vânia se deu da seguinte forma:

Cheguei ao salão de beleza e uma efeminada havia chegado na minha frente. Ela já tinha chamado a proprietária que morava no mesmo endereço e me pediu pra aguardar. Os cães latiam muito, estranhando a minha chegada junto ao portão. Ela também demonstrava estranhar a minha presença ali. $O$ estranhamento também foi visível da profissional de beleza que abriu a porta com cara de quem acabara de acordar. Era uma segunda-feira, aproximadamente onze horas da manhã. As duas me convidaram pra entrar e, meio sem jeito, disseram que eu poderia ficar à vontade. Eu disse que queria cortar o cabelo. Vânia, que era a proprietária, me perguntou quem havia feito a indicação. Eu, percebendo a falta de naturalidade das duas em me receber, disse que era gay e tinha acabado de chegar na cidade, que tinha muitas amigas travestis onde eu morava; e que perguntei para as pessoas da cidade: "Onde tem uma cabeleireira travesti pra cortar o meu cabelo?". Elas, automaticamente, ficaram mais à vontade e me pediram para sentar na cadeira e esperar o café. Enquanto o café estava sendo preparado por Vânia, a outra passava a vassoura no chão e limpava as fezes dos dois cachorros que a essa altura já me lambiam as pernas. A que limpava contava sobre uma 2 Nome fictício. 
recente decepção amorosa. Assim que o café ficou pronto, o serviu. Depois, Vânia colocou uma capa de estampa de onça sobre os meus ombros que caiu até os meus joelhos dobrados, dizendo-me: "Agora a senhora virou uma oncinha, chique né?". Rimos alto. A que limpava o chão bebeu o café e se despediu dela e de mim com beijinhos no rosto. Enquanto a outra arrumava o pente da maquininha de cortar cabelos, lhe perguntei sobre Corumbá, e o quanto a cidade poderia ser perigosa para uma bicha que acabara de chegar. Ela parou, me olhou pelo espelho e disse: "Aqui você não vai ter problema nenhum. Aqui é o Rio de Janeiro, querida".

De tudo o que há de bom para se pensar no relato apresentado anteriormente, destaco o fato deste pesquisador "ter virado uma oncinha" na cadeira do salão de beleza de Vânia, e a sua orientação de que Corumbá é o Rio de Janeiro.

É recorrente o entendimento de que, em termos de diferenças de classe, nacionalidade, gênero e sexualidade, em Corumbá "é tudo junto e misturado", ideia presente mesmo entre os próprios efeminados e efeminadas. Quando se questiona sobre os atos de discriminação e violência contra essas pessoas, esse entendimento da "mistura" de diferentes grupos aparece como a prova da não existência de violência/preconceito na cidade. Isso seria algo valorativo, associado ao Rio de Janeiro. É como se não existissem fronteiras excludentes, em certo aspecto, quando se pensa a diferença entre os habitantes em termos de gênero, sexualidade, classe e nacionalidade.

A ideia de que no Rio de Janeiro os efeminados e efeminadas não têm problema com a violência por preconceito de gênero e sexualidade me pareceu bastante interessante, ainda mais com a comparação em relação a Corumbá. Primeiro porque, do ponto de vista dos dados de violência carioca ${ }^{3}$, essa não é a realidade, e, depois, porque essa relação está para além das questões de gênero e sexualidade, afinal, em campo, ouvia sempre esta constatação a partir de outras características sempre positivas: estátua do Cristo no alto do morro ${ }^{4}$, carna-

3 Segundo os dados do Grupo Gay da Bahia, no Estado do Rio de Janeiro foram assassinadas 30 pessoas LGBT em 2016, destas, 8 foram na capital. Dados disponíveis em: https://homofobiamata. files.wordpress.com/2017/01/relatc3b3rio-2016-ps.pdf. Acesso em: 05 nov. de 2018.

4 Um dos pontos turísticos da cidade de Corumbá é o "Mirante Cristo do Pantanal", no morro do Cruzeiro, onde se encontra uma estátua do "Cristo Rei do Pantanal", com $12 \mathrm{~m}$ de altura. 
val $^{5}$, sotaque ${ }^{6}$, funk $^{7}$, calor $^{8}$, marinheiros e marinheiras ${ }^{9}$, moradoras e moradores cariocas ${ }^{10}$, samba, natureza exuberante, turistas, cerveja, torcedoras/es de times cariocas de futebol, aeroporto, construções históricas, hábito de usar roupas informais (curtas, leves, assim como chinelos e sandálias) para ir a bancos, lojas e supermercados, etc.

Em relação à referida "mistura" entre efeminados e efeminadas e os demais habitantes da cidade, segundo os próprios interlocutores e interlocutoras, ela se dá devido ao fato dessas pessoas estarem envolvidas em diferentes eventos, que atrai o público local e turistas, inclusive os/as bolivianos/as. Eventos esses que, em parte, são também identificados como existindo no Rio de Janeiro: os desfiles cívico-militares em comemoração à independência do Brasil e ao aniversário da cidade, além dos desfiles das escolas de samba durante o carnaval. Essas pessoas também estão envolvidas no concurso de quadrilhas durante a festa do Banho de São João ${ }^{11}$ e nas apresentações no Concurso de Bandas/Fanfarras das escolas. Mas também há aqueles eventos dirigidos especificamente à temática gay, como o Miss Gay, o Musa Gay do Carnaval e o Amistoso da Diversidade. Há, portanto, um regime de visibilidade que envolve efeminados/as e as demais pessoas entendidas como diferentes que compõem a identificação da cidade como sendo "tudo misturado/sem preconceito".

Na pesquisa em um sentido mais amplo, analisei o envolvimento e a participação dos efeminados e efeminadas nessas festivi-

5 O carnaval na cidade é bastante conhecido no estado de Mato Grosso do Sul, conta com 10 escolas de samba, algumas "filiadas" de escolas de samba cariocas.

60 "sotaque corumbaense" chama atenção por ser diferente das demais regiões do estado, assemelhando muito com o das/os cariocas e das/os portugueses. Maiores informações podem ser acessadas em reportagem jornalística disponível em: https://www.youtube.com/watch?v=zkgbYStoXhs. Acesso em: 05 nov. 2018.

7 Durante o trabalho de campo, o funk apareceu durante o pré-carnaval, o carnaval e algumas festas organizadas por grupo de moradores ou por empresários da cidade.

8 O calor da cidade a coloca com uma das mais quentes do país em diferentes noticiários nacionais. Em especial, durante o verão de 2015 , noticiou-se que duas pessoas teriam morrido devido ao clima. Informações disponíveis em: http://www.midiamax.com.br/noticias/933301-calor-teria-provocado-a-morte-de-duas-pessoas-em-corumba.html. Acesso em: 05 nov. 2018.

9 A Marinha tem sede na cidade vizinha, Ladário, mas a circulação de marinheiro pela cidade é intensa. 10 Devido à presença da Marinha na região, muitos militares são do Rio de Janeiro.

11 A festa em Corumbá segue a tradição que afirma que passar embaixo dos andores garante casamento, e quando os andores se encontram, há uma espécie de cumprimento entre eles, promovido pelas pessoas que os carregam. A Fundação de Cultura e Patrimônio Histórico de Corumbá, em parceria com a prefeitura, promove anualmente, com a publicação no Diário Oficial do Município, o cadastramento, recadastramento e certificação das/os festeiras/os, como agentes de preservação cultural. Por esses motivos, o banho de São João nas águas do rio Paraguai foi tomado pelo estado como patrimônio imaterial e aguarda reconhecimento para ser registrado como patrimônio imaterial nacional (Fernandes, 2018). 
dades, desde o planejamento à execução. No entanto, aqui, discutirei apenas parte da experiência correspondente ao Carnaval e ao Amistoso da Diversidade, via a participação de Vânia nesses dois eventos.

Para analisar as experiências constitutivas desse regime, eu, como pesquisador, precisei "virar oncinha" nas mãos de Vânia. O "virar oncinha" aqui não é no sentido de ultrapassar uma fronteira do humano e do não-humano, antes, pensar o quanto é "chique" estar sob a "pele de onça" (o tecido que me protegia dos fios de cabelos cortados). Essa experiência humano-animal tem sido produtiva do ponto de vista das análises que, conforme discutirei mais adiante, apontam os significados desse animal na região. Elas, em relação ao contexto pantaneiro-fronteiriço Brasil-Bolívia, tiram-me de um lugar supostamente confortável, de quem vai lá pesquisar, para alguém que lá é transformado em animal chique no primeiro contato com a interlocutora. Dito de outra forma, minhas preocupações teórico-analíticas tem sido no sentido do que tem provocado os saberes subalternos, isto é, segundo Larissa Pelúcio, "participar do esforço para promover uma outra gramática, outra epistemologia, outras referências que não aquelas que aprendemos a ver como 'verdadeiras', e, até mesmo, as únicas dignas a serem aprendidas e respeitadas" (2012, p. 399).

Nesse sentido, conforme apontou Pedro Paulo Gomes Pereira em relação às travestis de Santa Maria, não há como "simplesmente aplicar teorias alhures formuladas porque as formas de subjetivação aqui são outras" (2012, p. 389). Tem sido um exercício constante esse de "virar oncinha", isto é, me ver sob os olhos de Vânia, e de outros/as interlocutores/as fronteiriças/os que têm me colocado em um lugar de busca de novas formas de analisar as experiências vividas em campo por eles/as e, consequentemente, por mim. Afinal, "descontextualizar esses corpos e almas seria proceder um tipo de violência epistemológica que atua retirando aquilo que é mais caro para os sujeitos envolvidos, desprezando suas invenções e formas de agir” (Idem, 2012, p. 389).

\section{A ONÇA E A SUCURI NO PANTANAL}

A onça e a sucuri são animais presentes na cultura pantaneira. Eles estão marcados por uma historicidade que vai desde os 
primeiros habitantes indígenas que caçavam os animais silvestres por uma questão de subsistência, passando pelos 200 últimos anos em que os fazendeiros da região os abatiam para proteger o gado, até o momento mais contemporâneo e emergente da espetacularização da natureza, onde eles são transformados em objetos de desejo, em especial, a onça pintada (Ribeiro, 2015).

Ela, a onça,

é o maior felino do continente americano, e um animal de corpo robusto, dotado de grande força muscular, sendo a potência de sua mordida considerada a maior dentre os felinos de todo o mundo. Outra característica marcante dessa espécie é que ela não mia como a maioria dos felinos. Assim como o Leão, o Tigre e o Leopardo, ela emite uma série de roncos muito fortes que são chamados de esturro, que podem ser ouvidos por quilômetros ${ }^{12}$.

Mara Aline Ribeiro (2015) explica que basta navegar pelos sites das pousadas pantaneiras que se percebe essa espetacularização dos animais, em especial, da onça pintada. Em seu estudo sobre as gentes pantaneiras e a produção de geografias no Pantanal, a pesquisadora conta como um dos monitores ambientais cria expectativa nos turistas dizendo: "Ontem a pintada passou" ou "Hoje bem cedinho, antes de vocês acordarem, ela tava tomando água bem ali”. Além disso, segundo a autora, eles constroem fatos para garantir a satisfação do cliente. Por exemplo, relatam que um peão pega garrafas plásticas de refrigerante e, todos os dias, faz pegada de onça com o fundo da garrafa. Segundo o monitor conta, "Ele mente sério, não dá uma risada". Para Felipe Süssekind (2010), a onça é o animal mais procurado pelos guias nos passeios turísticos.

Após ter sido transformado em "oncinha" por Vânia, fiquei mais atento a presença desse animal na cidade pantaneira. Em uma ocasião, quando saía de casa, fui alertado via um programa de rádio local, da presença de onça na região da Universidade Federal de Mato Grosso do Sul (UFMS), onde eu deveria estar em poucos minutos. A cidade, no período da cheia do Rio Paraguai convive com a pre-

12 Disponível em: http://procarnivoros.org.br/index.php/animais/onca-pintada-panthera-onca/. Acesso em: 05 nov. 2018. 
sença desse animal de forma mais intensa. As manchetes dos jornais anunciam: "Trabalho de monitoramento e captura de onça entra no $11^{\circ}$ dia"13, "Onça-pintada morre atropelada na BR-262, perto da ponte sobre o Rio Paraguai"” " "Novos relatos apontam presença de onça-pintada na estrada que liga Corumbá a Ladário"15, "Onça encontrada em bairro de Corumbá, MS, sai da toca e some ${ }^{16 ",}$ entre outras.

$\mathrm{O}$ avistamento de serpentes também é recorrente, em especial a sucuri. As notícias em relação a esse animal sempre trazem desejo, curiosidade e temor, como as referentes à onça. Algumas manchetes anunciam: "Bombeiros registram recorde de invasão de cobras em cidade do interior de MS" Corumbá e é capturada pelo Corpo de Bombeiros ${ }^{18}$ ", "Sucuri de 3 metros é vista "passeando" pelo Porto Geral de Corumbá"19, entre outras. Ela, a sucuri,

[...] do pescoço até o rabo tem desenhos parecidos com a letra O Na cara ela tem dois riscos, um de cada lado. [...]. As Sucuris não são peçonhentas, ou seja, elas não matam usando veneno. Para caçar, elas esperam nas margens dos rios e quando a caça se aproxima para beber água, elas atacam no pescoço. Depois abraçam a presa e apertam, matando por constrição ou afogada dentro do rio ${ }^{20}$.

Aqui, diferentemente da ideia de "essência do selvagem", por sua representação de "pura" e "extrema" selvageria, compreendo a onça, assim como a sucuri, como performáticas e protéticas. Essa ideia, a partir da etnografia realizada, discutirei mais à frente. Antes, contudo, aponto para a necessidade e compreensão dos animais não como passivos, como um dado da "natureza" pantaneira, antes, como múltiplos, híbridos, ativos, conforme a reflexão de Felipe Süssekind

13 Disponível em: https://diarionline.com.br/?s=noticia\&id=70632. Acesso em: 05 nov. 2018.

14 Disponível em: https://www.campograndenews.com.br/reporter-news/onca-pintada-morreatropelada-na-br-262-perto-da-ponte-sobre-o-rio-paraguai. Acesso em: 05 nov. 2018.

15 Disponível em: https://diarionline.com.br/?s=noticia\&id=95669. Acesso em: 05 nov. 2018.

16 Disponível em: http://g1.globo.com/mato-grosso-do-sul/noticia/2014/08/onca-pintada-que-apareceu-em-bairro-de-ms-sai-da-toca.html. Acesso em: 05 nov. 2018.

17 Disponível em: https://www.midiamax.com.br/cotidiano/2018/video-caninana-tenta-entrar-em-casa-de-morador-no-interior-de-ms/. Acesso em: 05 nov. 2018.

18 Disponível em: https://g1.globo.com/mato-grosso-do-sul/corumba-e-regiao/noticia/sucuri-para-o-transito-em-avenida-de-corumba-e-e-capturada-pelo-corpo-de-bombeiros.ghtml. Acesso em: 05 nov. 2018.

19 Disponível em: https://diarionline.com.br/?s=noticia\&id=93115. Acessado em: 05 nov. 2018

20 Disponíveis em: https://pt.wikibooks.org/wiki/Bichos_da_mata/Sucuri. Acessado em: 05 nov. 2018. 
(2010) sobre o gado das/nas fazendas no Pantanal. Para esse autor,

O manejo intensivo dentro do mangueiro, em episódio de vacinação e contagem dos animais, são aspectos de produção produtiva, são momentos nos quais o gado é tratado como coisa, objeto, rebanho indiferenciado. Ao mesmo tempo, a lida com os animais no campo é atravessada pela diferenciação, pelos indivíduos excepcionais, brados, que varam cerca, escapam do rebanho, pelos cavalos difíceis de domar, pelas reses reivindicadas pelas onças, pelas enchentes e pelas cobras (Idem, p. 111).

Assim, os animais aqui são vistos como agindo de forma cultural-natural. No caso da onça, ela vive "rondando" a cidade, sendo procurada pelos turistas, "fugindo" da captura, "causando acidente" quando é atropelada na estrada. A sucuri, por sua vez, "passeia" pelo porto, "para o trânsito", "aparece" na área urbana cada vez em maior número. Os animais interagem, têm vida, possuem nome-identidade (como discutirei adiante), constituindo, nesses termos, relações com a cidade e as pessoas, não apenas são a "natureza" do Pantanal.

Para além das experiências desses dois animais noticiados nos jornais, o marco da espetacularização da onça e da sucuri se deu com a novela Pantanal, lançada em 1990, na então Rede Manchete.

Os debates e os discursos produzidos sobre Pantanal recaíam sobre as constantes cenas de nudez e sexo. A novela diferenciou-se de outras por fazer do erotismo uma das marcas da televisão brasileira, naquele momento, um impacto que ainda não havia sido experimentado na história da mídia televisiva brasileira (Klanovicz, 2010, p. 151).

Ela contava a saga da mulher que se transformava em onça pintada, Juma Marruá, interpretada por Cristiana Oliveira ${ }^{21}$. Essa transformação ocorria todas as noites, na abertura dos capítulos, interpretada por Nani Venâncio, que aparecia nua mergulhando em um rio. A onça se encontrava, em dado momento da abertura, com uma enorme sucuri ${ }^{22}$.

21 Disponível em: https://observatoriodatelevisao.bol.uol.com.br/historia-da-tv/2018/03/o-grande-sucesso-pantanal-estreava-ha-28-anos. Acessado em: 05 nov. 2018.

22 Abertura da novela disponível em: https:/www.youtube.com/watch? $\mathrm{v}=\mathrm{hfth} 1 \mathrm{z} 2 \mathrm{rHB} 8$. Acessado em: 05 nov. 2018. 
Pantanal foi um marco da TV brasileira. Pela primeira vez, uma novela era praticamente toda gravada em externas, fazendo de sua paisagem um personagem importante da história. Mérito não apenas do autor, Benedito Ruy Barbosa, um perito em tramas rurais, como também do diretor Jayme Monjardim, que conseguia extrair poesia das belas imagens mostradas. Além disso, a trama apostava fundo na sensualidade, com muitos corpos despidos em banhos de rio. O pioneirismo agradou o público, e Pantanal alcançou índices de audiência inimagináveis para a Manchete, batendo nos 40 pontos no Ibope. Exibida às $21 \mathrm{~h} 30$, a novela chegava a bater a Globo, que se viu obrigada a cancelar sua linha de shows e lançar uma nova novela para enfrentar a concorrente. Assim, programas como TV Pirata saíram do ar, e entrou em cena a novela Araponga, de Dias Gomes. Não deu certo ${ }^{23}$.

A onça não era o único animal associado à personagens humanas na novela. A sucuri também se misturava a identidade do "velho do rio", personagem misterioso interpretado pelo já falecido ator Cláudio Marzo. Fora do foco das câmeras de TV, a sucuri se chamava Rafaela, pertencia ao Instituto Vital Brazil ${ }^{24}$, e também já morreu. Em relação a dar nomes aos animais, tem sido comum a prática para com as onças, em especial aquelas capturadas por cientistas na coleta de material biológico no Pantanal, assim como no trabalho dos guias turísticos nas fazendas pantaneiras (Süssenkind, 2010).

Em relação à Rafaela, ela media 5,5 metros e pesava 90 quilos. Segundo o que noticiaram, "brilhou na telinha da TV Globo", na minissérie Mad Maria, e "participou” também dos programas Caldeirão do Huck e Balanço Geral, no qual fez sua última aparição na TV no dia 11 de maio de 2012. Mas, mesmo com todas essas aparições,

Rafaela teve o auge da fama quando, em 2002, revolucionou as leis da Biologia por ter dado a luz sem ter cruzado. Até hoje não se achou nenhuma explicação para o caso. Outra época em que teve seu nome na mídia foi quando, para se esquentar, acabou matando a colega de jaula durante a madrugada, ao "abraçá-la" fortemente ${ }^{25}$.

23 Disponível em: https://observatoriodatelevisao.bol.uol.com.br/historia-da-tv/2018/03/o-grande-sucesso-pantanal-estreava-ha-28-anos. Acesso em: 05 nov. 2018.

24 Informações sobre o Instituto Vital Brasil estão disponíveis em: http://www.vitalbrazil.rj.gov. br/. Acesso em: 15 fev. 2019.

25 Disponíveis em: https:/extra.globo.com/noticias/rio/morre-sucuri-que-participou-da-novela-395918.html. Acesso em: 05 nov. 2018. 
Assim, com aparições na TV, e comportamentos tão diversificados, Rafaela e a onça pintada não podem ser entendidas como passivas e não ativas nas suas relações entre si, com as pessoas, fora e dentro da novela. Isso parece-me fundamental para compreender protéticamente e performaticamente as experiências da travesti Vânia no contexto pantaneiro.

\section{A SUCURI E O AMISTOSO DE FUTEBOL}

Foi divulgando na cidade, por meio de cartazes impressos e também compartilhados nas redes sociais, o Amistoso da Diversidade do ano de 2014. Um dos efeminados que conheci no Miss Gay Corumbá me ofereceu uma carona até o bairro onde o evento ocorreria.

Chegamos de carro no Centro Comunitário Guató. Era domingo à tarde e fazia calor. Centenas de pessoas já haviam chegado. A entrada custava dois reais, e, assim que pagamos o ingresso, passamos por duas colunas de bexigas coloridas, e uma bandeira gay com mais de dois metros de altura por uns três de comprimento. Um grupo de pagode tocava ao vivo na área coberta, em uma das quadras. Enquanto as pessoas adultas conversavam e bebiam, as crianças brincavam em grandes escorregadores infláveis e camas elásticas, em uma outra quadra, no mesmo espaço coberto. O evento era denominado " $10^{\circ}$ Amistoso da Diversidade". O interlocutor que me levou até lá, assim que entrou no centro comunitário foi abraçado longamente por uma mulher e disse: "Que bom te encontrar aqui!". Ela, rapidamente, respondeu: “'Claro né!?' Eu disse assim: 'nunca tem nada nessa cidade, quando tem, a gente tem que ir né!". Ele, o efeminado, concordou e riu. Em seguida, ele perguntou sobre uma mulher conhecida deles, e ela contou que essa amiga não quisera vir. Segundo ela, essa conhecida disse a ela: "Eu não vou ver bicha não, só se for ir para dar risada". Ela, que nesse momento segurava na mão do efeminado, disse ter respondido à amiga: "Mas é pra isso mesmo!". Rimos alto os três, eu, ele e a mulher.

O espaço comunitário já estava lotado quando o jogo de futebol começou, no campo gramado, no final da tarde, com direito à torcida pelos dois times, os da cidade de Ladário contra os de Corumbá. 
O evento durou até o anoitecer. Cada vez mais o público se envolvia com a partida, sempre muito animado. Muitas pessoas levaram cadeiras de casa, alguns homens ficaram sentados em suas bicicletas, outros se espremiam junto ao alambrado que cercava o campo de futebol para não perder nenhum lance. Havia também muitas mães com crianças, algumas maiores, outras em seus carrinhos de bebês. $\mathrm{O}$ riso era característica marcante na plateia. Se os/as jogadores/as efeminados/as, contrariando a expectativas das pessoas presentes, acertavam o lance, driblando ou roubando a bola do time adversário, o público, surpreso, gritava e ria alto, se elas/eles cometiam erros nos passes ou desrespeitavam alguma regra, o que era esperado por muitos/as não serem habituados/as a jogarem futebol, ocorria o mesmo, o público se divertia muito. Já os/as jogadores/as, pareciam levar a partida a sério.

Logo no início do jogo eu encontrei Vânia com uma cobra sucuri de pelúcia enrolada nos ombros, tirando foto com pessoas conhecidas que se aproximavam rindo, cumprimentando-a. Eram homens e mulheres de diferentes idades. Ela chamava a atenção do público ao caminhar próximo da grade. Cumprimentou-me com um beijo, oferecendo a cabeça da cobra para eu beijar, ao mesmo tempo que me pedia ajuda para tirar mais uma foto dela com as pessoas presentes. Ela usava um vestido vermelho até os joelhos, com decote comum para um dia quente. Após o jogo, já à noite, ela se apresentou em um palco, antes da banda voltar a tocar, rodeada de muita gente, em especial, crianças pequenas. A cobra permanecia com ela, mas tinha trocado o vestido por um todo dourado e brilhante. Fazia parte da apresentação manusear a cobra, no entanto, na parte final a sucuri ficou jogada no chão. O público ria e aplaudia bastante.

Em campo, o riso voltado aos efeminados e efeminadas, nos diferentes eventos que pude participar, não tem consenso em relação ao seu significado, se é algo bom ou ruim. Os/as interlocutores/as divergem se é ou não algo respeitável, positivo em relação ao reconhecimento que buscam. Não há fronteira fixa para o riso. Sendo assim, reconheço a ambivalência (os múltiplos sentidos) do riso na contemporaneidade, o que, de certa forma, todos os intelectuais do século XX que se dedicaram a estudar esse tema fizeram (Minois, 2003). 
Esta ambiguidade está dada pelo contexto cultural em que estas experiências são produzidas, para além da realidade específica da fronteira. Assim, seja em Corumbá ou em outra cidade, para compreendermos e rirmos com uma piada, segundo Sírio Possenti (1998), é preciso conhecer os traços da cultura, assim como para entender histórias infantis, mitos locais, receitas culinárias, aspectos da legislação, regras políticas, ou o que gritam os torcedores de times de futebol nas tardes de domingo. Este autor nos oferece uma pista importante para pensarmos os efeitos ambivalentes da travesti com a cobra sucuri. Ele afirma que "o que faz que uma piada seja uma piada não é o seu tema, sua conclusão sobre o tema, mas uma certa maneira de apresentar tal tema ou uma tese sobre tal tema" (Idem, p. 46).

Nesse caso, a cobra faz referência a inúmeras interpretações, no entanto, destaco duas: primeiro, ao próprio corpo da travesti, que, mesmo reconhecidamente feminino (próteses de silicone, cabelos longos, vestido, salto alto, performance feminina), sabidamente possuía um pênis, órgão comumente associado, e muitas vezes nomeado como cobra nos contextos nacionais; segundo, ao fato de a performance ser em tom jocoso, provocador diante do que se fazia com a cobra enrolada no corpo, também algo comumente presente em cenas de modelos mulheres em fotografias ou shows eróticos.

Aqui se trata, portanto, de uma travesti performatizando algo caricato. A caricatura, em apresentações públicas, é comum em algumas drags.

De forma geral, o que diferencia as drags de outras performances de gênero são aspectos como temporalidade, corporalidade e teatralidade. Temporalidade porque a drag tem um tempo "montada", outro "desmontada" e, ainda, aquele em que "se monta". Diferentes das travestis e transexuais as mudanças no corpo são feitas, de modo geral, com truques e maquiagem (Vencato, 2003, p. 196).

Nesse caso, ainda que não se trate de uma drag, a travesti apresentou-se de forma caricata, e conquistou o reconhecimento do público, desde o momento que chegou no amistoso até os aplausos 
finais do show. Vânia, como comumente nas apresentações de drags "caricatas", fugiu ao estereótipo de beleza feminina quando, ainda que feminina, apresentou em público a sua cobra sucuri de pelúcia sem ser como as modelos femininas que comumente seduzem o público dançando ou fotografando-se com uma cobra. Como o perfil de drag citado aqui, ela provocou o interesse em ser fotografada, o riso e o aplauso do público em uma situação nada "glamourosa", inclusive pelo contexto do amistoso que já é risível para boa parte de quem se fazia presentes.

\section{A ONÇA E O CARNAVAL}

No ano de 2015, durante as apresentações das escolas do grupo especial do "Carnaval da Alegria"26, reencontrei Vânia em uma de suas apresentações. Ela desfilou em uma das escolas e, novamente, recebeu muitos aplausos das pessoas, acompanhados de sorrisos.

Naquela noite, cheguei cedo na "Passarela do Samba" ${ }^{27 "}$ para poder sentar na arquibancada de acesso livre, destinada às pessoas e turistas que não compraram convite para o camarote, que estava do outro lado da rua, e em um nível superior ao último degrau da arquibancada onde eu estava. Assim, de onde fiquei, podia ver bem o desfile e as reações tanto da "comunidade" como da "sociedade" corumbaense, bem como turistas, dos dois lados da rua.

A diferença entre a "comunidade" e a "sociedade" tem relação com classe econômica. Não se trata aqui de uma diferenciação teórica, do campo das Ciências Sociais. Antes, são termos êmicos usados em campo de forma bastante distinta. Um exemplo é o Amistoso da Diversidade, que é na e para a "comunidade", isto é, realizado na periferia e com a ajuda de comerciantes de pequenos estabelecimentos e lideranças de bairros periféricos. Outro é o Miss Corumbá Gay, que foi pensando para a "sociedade", porque contou com apoio e presença do empresariado local, inclusive, em 2014, foi realizado no Corumbaense, clube tido historicamente como de elite, chique.

26 O Carnaval de Corumbá é chamado também de Carnaval da Alegria em peças publicitárias produzidas pelo estado.

27 A "Passarela do Samba" envolve inclui a Rua Frei Mariano e a Avenida General Rondon até a Rua Major Gama, no centro de Corumbá. 
Essa diferença não é explícita, nem anunciada de forma objetiva em campo. Essa diferenciação é dado de pesquisa etnográfica. Seja um ou outro, esses eventos têm forte presença de efeminados/a na criação, organização e execução, mas um público sempre majoritariamente não gay, não lésbico ou não travesti. Já ouvi em campo que "o evento é feito por gay, mas não para um público gay".

Em relação aos/às turistas, eles/as são muito importantes para a cidade, em especial - para além dos fatores econômicos que são gerados pelas visitas - a valorização da região fronteiriça pelo olhar do "de fora", sendo algo essencial em um contexto demarcado por preconceitos e estigmas por ser fronteira. Isso se dá, por exemplo, pelo fato de, nesse caso, as fronteiras sul-mato-grossenses serem as mais utilizadas e preferidas pelos contrabandistas de armas e compradores de drogas, afinal, essas fronteiras são extensas e contam com pouco policiamento (Esselin et al., 2012). Além disso, “o desenvolvimento do turismo foi envolvido de problemas sociais, como a exploração sexual comercial de crianças, de enorme gravidade" (Lamoso, 2012, p. 164).

Vânia, quando apareceu desfilando na passarela, apresentava-se vestida apenas como um macacão justo ao corpo, uma espécie de segunda pele, estampado como se fosse uma onça. As pintas/ marcas e as orelhinhas discretas sobre a cabeça, o rabo de onça da fantasia e o cabelo todo preso em formato de coque sob o mesmo tecido estampado que cobria o corpo, não restava dúvida: era uma onça pintada sambando na avenida.

Ela puxava um estandarte que, de um lado, onde ela se posicionava, via-se um sol iluminado, do outro, um enorme rosto de uma onça pintada. Esse elemento alegórico tinha aproximadamente três metros de altura, era em formato circular, com toda a borda repleta de plumas verdes, sendo uma marca de glamour durante o carnaval no Brasil. Ela, sozinha, em destaque no chão, o conduzia, sempre como se ele formasse uma espécie de costeiro, com rodinhas, quase acoplado a sua fantasia.

Segundo os interlocutores de Passamani (2018), para homens “com condutas homossexuais" moradores de Corumbá e Ladário, o carnaval local representa o glamour para as bichas, isto é, como momento 
de realização de fantasias e sonhos, "seria o 'palco iluminado' de todas as bichas que sempre perderam na vida".(idem, p. 90 grifo do autor).

Esse glamour pode ser observado com a reação do público diante de Vânia. Os gritos, aplausos e sorrisos vinham dos dois lados da rua, tanto da "sociedade", no alto do camarote, que a aplaudia de pé, como da "comunidade", na arquibancada popular, onde eu me encontrava. $\mathrm{O}$ macacão agarrado ao corpo não tinha nenhum decote, deixando a mostra apenas o rosto e as mãos, marcando a sua cintura tida como feminina e os peitos. Ela era uma das foliãs mais fotografadas da noite.

O carnaval em Corumbá é um dos eventos, em relação aos citados aqui no início desse artigo, que mais tem público, inclusive, é o que mais reúne efeminados/as, em suas diferentes fases de realização. Ele também é, pelas minhas observações, o que mais atrai bolivianos e bolivianas à cidade. Em relação ao estado de Mato Grosso do Sul, a sua importância é enorme; por exemplo, devido aos cortes de verba, o Governo do Estado em 2019 irá patrocinar apenas a festa da Capital e a da Cidade de Corumbá, por ser as duas maiores ${ }^{28}$.

A visibilidade das efeminadas e efeminados em Corumbá, e a ideia de ser uma cidade sem preconceitos e violência está em oposição às interpretações sobre o "outro lado". Para alguns interlocutores/as, não haveria efeminadas/os bolivianas/os na região: "aqui nós fazemos fronteira com os índios, não há, não tem nada lá, só índios, roupas, coisa pra comprar mesmo" 29 . A frase "lá não tem gay" também apareceu algumas vezes em campo.

Com minha insistência em querer saber das/os interlocutoras/ os brasileiras/os sobre o outro lado da fronteira, um disse-me em relação ao país vizinho: "Aqui na fronteira não tem gay não, nunca vi, só lá em Santa Cruz"30".

"Fronteira" aqui aparece como em outro estudo, nomeando o

28 Disponível em: https:/www.campograndenews.com.br/cidades/capital/estado-prioriza-saude-e-cancela-parte-dos-investimentos-no-carnaval/2019. Acessado em 10 fev. 2019.

29 Sobre o imaginário da fronteira por moradores jovens de Corumbá, Edgar Ap. da Costa (2013) desenvolve um estudo que aponta para dados duais em relação à fronteira (leia-se "a cidade vizinha"), isto é, ainda que suja, desorganizada, perigosa, feia, também um espaço para compras, lazer e trocas culturais.

30 Santa Cruz, na Bolívia, está distante aproximadamente $400 \mathrm{~km}$ de Corumbá, e possui mais de 1.700.000 habitantes, segundo o site Wikipedia. Durante uma rápida visita, pude perceber que além de organizações da sociedade civil e do movimento social da diversidade sexual, nesta cidade também há sauna e boate voltada ao público gay. 
lado do país vizinho (Costa, 2013). É como se a fronteira tivesse apenas o lado do "outro". Portanto, certa invisibilidade "estratégica" caracteriza parte do discurso sobre o "outro" quando se trata de gêneros dissidentes e sexualidades disparatadas. "As relações entre Brasil e Bolívia, mesmo carregadas de acidentes e de recíprocas desconfianças, foram direcionadas sempre no sentido da submissão daquele país aos interesses continentais do Brasil" (Esselin et al., 2012, p. 153).

Utilizo "estratégica" aqui no sentido do que esta invisibilidade (ou apagamento) possibilita, nos termos da produção de diferenças, não necessariamente consciente e calculada, mas como altamente produtora de significados nos contextos das relações de poder local, isto é, caracteriza um tipo de regime de visibilidade.

Por exemplo, a questão de existir "só índios", de "não ter nada lá", de ter gays somente na populosa Santa Cruz pode ser lida como se a vizinhança boliviana da fronteira fosse "preconceituosa", neste caso, em termos das práticas de gêneros dissidentes e sexualidades disparatadas, em contraposição a Corumbá, "que é o Rio de Janeiro".

Essa produção diferenciada de identidade fronteiriça tem relação direta com a ideia de nação. Octavio Ianni (1988) definiu nação como estando sempre em movimento, afinada e desafinada, não surgindo e nem permanecendo pronta e acabada.

Nasce e renasce, segundo o movimento do seu povo, forças sociais, formas de trabalho e vida, controvérsias e lutas, façanhas e utopias. Resgata ou esquece tradições reais e imaginárias, conforme a fisionomia que se pretende construir no presente, segundo a utopia que vai buscar no futuro. $(1988$, p. 31)

Esse movimento corrobora-se contrariando as avaliações sobre o "outro", ou diversificando-as, afinal, pude manter contato através da sala UOL ${ }^{31}$ Corumbá, e depois do Facebook, com uma travesti de Puerto Quijarro. Através das redes socais e de esparsos encontros em Corumbá, pude acessar parte da rede de sociabilidade dela, das duas cidades bolivianas, formada também por outras efeminadas e

31 Refiro-me à sala de bate papo online, do site UOL, onde as pessoas trocam mensagens de texto, imagem e áudios, conforme o interesse. Não necessariamente é obrigatório identificar-se para participar das trocas de mensagem. 
efeminados de lá. Além disso, segundo matéria jornalística, no ano de 2012, foi realizado o quarto "Miss Pantanal Gay", com participação, pela segunda vez, de representantes das cidades bolivianas de Puerto Quijarro e Puerto Suárez ${ }^{32}$. Segundo a mesma fonte, o organizador do desfile afirmou que isso mostra uma integração entre os povos que vivem nessa faixa fronteiriça.

\section{DAS PERFORMANCES PROTÉTICAS PANTANEIRAS}

Mesmo considerando o que afirma Judith Butler, que "o gênero é sempre um feito, ainda que não seja obra de um sujeito tido como pré-existente à obra" (2003, p. 48). Dito de outro modo, ele é um "estilo corporal, um 'ato', por assim dizer, que tanto é intencional como performativo, onde 'performativo' sugere uma construção dramática e contingente do sentido" (Idem, p. 199). A performance de gênero se dá também por elementos que estão além do ato reiterado em si, como, por exemplo, as diferentes tecnologias (Preciado, 2018). Parte destas tecnologias são protéticas. Penso prótese de gênero não como sendo essência, mas como trânsito. É um efeito múltiplo e não tem uma origem única (Preciado, 2002). Isso corrobora o quanto "a prótese é um acontecimento de incorporação", como tantas outras zonas de produção do gênero. "Historicamente, é a única forma de 'ser corpo' em nossas sociedades pós-industriais. A prótese não é abstrata, não existe se não aqui e agora, para este corpo e neste contexto" (Idem, p. 168).

Nesse sentido, a sucuri e a onça pintada são próteses de gênero nas experiências performáticas de Vânia, e na minha também, transformado em "oncinha" na cadeira do salão de beleza dessa interlocutora. A nova gramática, ainda em formas expressionistas, permite-me refletir em termos de performance e prótese via uma torção dos conceitos de "performance de gênero" e "prótese de gênero" definidos anteriormente.

Como apresentado, com a espetacularização da natureza no Pantanal, esses animais fazem parte da cultura local de um modo bastante importante, não apenas como objeto de desejo e curiosida-

32 Mais informações disponíveis em: http://www.diarionline.com.br/index.php?s=noticia\&id=42694 Acessado em: 09 nov. 2018. 
de, mas, às vezes, como ameaça e temor. Há um processo protético e performático dessa interlocutora com esses animais, que implica no reconhecimento dela, tanto diante da "comunidade", quando se apresentou com a sucuri/risível, como da "sociedade", quando se fantasiou de onça pintada/chique.

Nesse sentido, o reconhecimento é algo que se dá necessariamente por um caminho comum entre histórias singulares, e esse caminho o coloca em circulação (Butler, 2007). Isso porque "o reconhecimento é uma relação intersubjetiva, e, para um indivíduo reconhecer o outro, ele tem que recorrer a campos existentes de inteligibilidade" (Butler, 2010, p. 168). Nada mais inteligível na fronteira pantaneira do que uma onça pintada e uma sucuri, nesse caso, no corpo de uma efeminada (travesti).

Esse regime de visibilidade via a experiência de travestilidade discutida nesse artigo, nos termos aqui apresentados, torna-se ainda mais significativo em um contexto onde o trabalho de campo mostrou que, diferente do olhar "nativo", parte da cidade é preconceituosa e violenta com travestis e outros/as efeminados/as. Por exemplo, no próprio cartaz do amistoso de futebol, que chamava a população para ir assistir e torcer para um dos times em campo, lê-se: "A festa da alegria contra o preconceito". Algumas manchetes também denunciam esse clima de violência na cidade: "Travesti de 29 anos é assassinado com facada no pescoço"33, "Após assumir namoro com travesti, homem é agredido no centro de Corumbá" ${ }^{34}$, "Parada da Cidadania e Show da Diversidade reforçam combate à homofobia" 35 , entre outras.

Vânia, nesse contexto, a partir da onça pintada e da sucuri, apresenta uma possibilidade de agenciamento em prol do reconhecimento. A agência diz respeito às "possibilidades no que se refere à capacidade de agir, mediada cultural e socialmente" (Piscitelli, 2008, p. 267). Há, portanto relação direta com as relações de poder, com o que é visível e aceitável na vida cotidiana, isto é, com os regimes de visibilidade. Isso ocorre, como discutido aqui, diante de vários elementos de identificação e diferenciação no contexto fronteiriço 33 Disponível em: http://www.correiodoestado.com.br/noticias/travesti-de-29-anos-e-assassinado-com-facada-no-pescoco/193917/. Acesso em: 05 nov. 2018.

34 Disponível em: http://www.capitalnews.com.br/policia/apos-assumir-namoro-com-travesti-homem-e-agredido-no-centro-de-corumba/277439. Acesso em: 10 jun. 2017.

35 Disponivel em: https://diarionline.com.br/?s=noticia\&id=97198. Acesso em: 05 nov. 2018 
pantaneiro, como os dois animais em questão. Ela incorpora esses elementos como espécies de próteses de gênero tipicamente nacionais, indo além de um farmacopoder transnacional (Preciado, 2018).

A farmacopornografia é um regime pós-industrial, global e midiático. "O termo se refere aos processos de governo biomolecular (fármaco-) e semiótico-técnico (pornô) da subjetividade sexual, dos quais a Pílula e a Playboy são dois resultados paradigmáticos" (Idem, p. 36). Para Preciado,

O biocapitalismo farmacopornográfico não produz coisas, e sim ideias variáveis, órgãos vivos, símbolos, desejos, reações químicas e condições de alma. Em biotecnologia e pornocomunicação não há objeto a ser produzido. O negócio farmacopornográfico é a ivenção de um sujeito e, em seguida, sua reprodução global (Idem, p. 38).

No entanto, como já dito, não adianta simplesmente aplicar teorias não produzidas a partir dessa experiência de travestilidade pantaneira-fronteiriça, porque aqui há outras formas de subjetivação que não as estudadas pelos autores e autoras comumente usados.

Isto é, considerando a experiência de Vânia, mesmo em um contexto global de capitalismo farmacopornográfico, o seu processo de reconhecimento se dá não dependendo exclusivamente dos suportes técnicos, farmacêuticos e midiáticos desse tipo de capitalismo, isto é, há invenções e formas de agir a serem entendidas via outras epistemologias, para além de um sujeito reproduzido de forma global. Isto é, por meio de experiências protéticas de elementos não passivos, mas múltiplos, híbridos e ativos, capazes de gerar performatividade das suas ações, como é o caso da onça pintada provocando a performance protética de um peão marcando com garrafa de refrigerante (aqui pensada como prótese) o que seria o andar/pegada da onça no Pantanal, ou, ainda, de "provocar/confundir" a Biologia, como o fato de Rafaela ter procriado sem contato com um macho da sua espécie.

Vânia, de forma protética, nos termos aqui discutidos, juntamente com a performance feminina, materializa um corpo (Butler, 2001): travesti risível, mas não abjeto, merecedor de aplausos, nos dois eventos, e de públicos distintos. O riso, como já dito, aparece 
em campo como sendo, para alguns e algumas, um sinal de reconhecimento, logo, de não preconceito. Para outros e outras, uma minoria em campo, ele configura o oposto, isto é, a prova da existência do preconceito. Portanto, ainda que tenha interpretações variadas, logo, significados ambíguos, é inegável, mesmo em Corumbá, que se viva em uma "sociedade humorística".

Georges Minois, baseado em Gilles Lipovetski, caracteriza a "sociedade humorística" como uma sociedade onde "o riso é receita eleitoral, argumento publicitário, garantia de audiência para os meios de comunicação e até uma incitação à ação caritativa [...]" (Minois, 2003, p. 594). É uma sociedade que se banha no culto da descontração divertida. E isso tem tudo a ver com a sociedade de consumo, que é, antes de tudo, eufórica.

No entanto, ainda que exista uma espécie de comercialização do riso, e, por isso, segundo Minois (2003), ele possa estar em perigo, vítima do seu próprio sucesso, é preciso minimizar a caracterização que se faz desta "sociedade humorística" em meio a uma visão "desenvolta do mundo", afinal, discordo da percepção pessimista de que o riso tenha estado "moribundo" ou "vazio" em nosso tempo por ter se transformado em "fogo de palha generalizado, numa sociedade de consenso fraco" (Idem, p. 620).

O trabalho de campo no contexto fronteiriço permite refletir que o equívoco desta percepção "aplicada" a outras realidades esteja na noção de que viemos em uma sociedade necessariamente de "consenso fraco", "rasa". Porque não teríamos mais aquilo que trazia vigor ao cômico, os contrates com o sério: seriedade do Estado, da religião, do sagrado, da moral, do trabalho, da ideologia. Penso ser necessário não generalizar o que Gilles Lipovetski chama de "era do vazio":

Um novo estilo descontraído e inofensivo, sem negação e nem mensagem, apareceu. Ele caracteriza o humor da moda, do texto jornalístico, dos jogos radiofônicos e televisivos, do bar, de numerosos BD. O cômico, longe de ser a festa do povo ou do espírito, tornou-se um imperativo social generalizado, uma atmosfera cool, um meio ambiente permanente que o indivíduo suporta até em sua vida cotidiana. (Lipovetski apud Minois, 2003, p. 620). 
Afinal, os dados de violência e preconceito em relação ao "outro", seja boliviana/o e/ou travesti, nos contextos fronteiriços, mostram o contrário. Por exemplo, além do que já foi citado aqui, em termos de jovens efeminadas/os, o estudo de Sanderson Fardim Fernandes (2018) apontou que a ambiguidade da visibilidade lida como positiva desses jovens via a participação em atividades escolares da cidade, como as fanfarras e as quadrilhas juninas, não garante a permanência contínua na sala de aula, durante toda a formação educacional, assim como indica uma real ameaça de expulsão de casa por parte dos familiares.

\section{CONSIDERAÇÕES FINAIS}

Pelo que foi discutido, Vânia soube usar os códigos e valores da gramática local, das estratégias de gestão da visibilidade, tanto diante da "comunidade" como da "sociedade", inclusive diante de um "outro" tido como menos valioso, estrangeiro. Afinal, para além dos animais, o carnaval e o futebol são marcas de nacionalidade. Eles, associados ao reconhecimento dos efeminados e efeminadas na cidade, via a participação das mesmas nessas atividades, em seus discursos e no dos demais interlocutores e interlocutoras, apresentam-se como uma diferenciação fronteiriça entre Brasil (sem preconceito) e a Bolívia (preconceituoso).

Eu ter virado "oncinha", algo chique na visão de Vânia, durou pouco. Assim que ela terminou o serviço, e eu me vi no espelho sem o tecido estampado como pele de onça sobre o corpo, observei que ela havia feito um corte de cabelo que é habitualmente usual entre os guris (homens jovens e másculos de Corumbá), isto é, muito parecido com os jovens da Marinha.

Antes de eu falar que tinha gostado do trabalho dela, mesmo tendo sido feito de forma diferente do que eu havia solicitado, ela me fez uma proposta inesperada: "Não conte para mais ninguém que você é gay aqui na cidade, até eu e você sairmos para dar uma volta no meu carro, só para passearmos nos bares, para as bichas ficarem morrendo de inveja de mim. Você ficou igualzinho aos guri aqui da cidade com esse corte". A onça, como outras próteses, por ser 
contextual e histórica, assim como a sucuri, tem a capacidade performática, de nos efeminizar, como de nos masculinizar. Parte dessa capacidade tem relação direta com a vida e a movimentação dos próprios animais, não somente do nosso olhar cultural sobre eles, diferentemente de outras próteses não vivas.

A fronteira identitária em termos de gênero e sexualidade que as/os efeminados apresentam, sendo gays e/ou travestis, masculinas/ os e/ou femininas/os, que tem implicação na caracterização moral da própria região em relação ao "outro lado" da fronteira nacional, onde o próprio nacional é fronteiriçamente marcado por intersecções da presença e ausência dos efeminados e efeminadas, apresentou-se rentável para a produção, ainda ensaísticas, de novas epistemologias. Além disso, a ideia de fronteira performaticamente e protéticamente pantaneira, isto é, relacionando animais e humanos, estão no campo de forma a envolver e transformar o próprio pesquisador. O processo de reconhecimento, risível ou não, nesses termos, também se apresenta como uma experiência de fronteira, abrangendo diferentes marcadores sociais da diferença em contexto de relações de poder/ valoração diversificadas.

Assim, é possível concluir que, mesmo em contextos de violência diante de experiências de gêneros dissidentes e sexualidades disparatadas, a diferença não necessariamente é um elemento depreciador (Brah, 2006). Ao invés disso, serve para pensar as normas e convenções de constituição de uma nacionalidade valorizada diante de um "outro" depreciado, assim como em performances protéticas tipicamente pantaneiras em uma cidade que, ao mesmo tempo que invisibiliza características fronteiriças, produz uma fronteira capaz de identificá-la, estrategicamente, com sendo o Rio de Janeiro e onde é "tudo junto e misturado".

\section{REFERÊNCIAS}

BANDUCCI JÚNIOR, A. O Pantanal e a sua gente: diversidade étnica e cultura. In: MORETTI, E. C.; BANDUCCI JUNIOR, A. (Orgs). Pantanal: territorialidades, culturas e diversidade. Campo Grande, MS: Ed. UFMS, 2012. p. 09-23. 
A travesti, a onça pintada e a sucuri:

Reflexões sobre regime de visibilidade no Pantanal, MS.

BARROS, M. Gramática Expositiva do Chão. Rio de Janeiro: Record, 1996

BRAH, A. Diferença, diversidade, diferenciação. Cadernos Pagu, 26, p. 329-376, 2006. Disponível em: http://www.scielo.br/pdf/cpa/ n26/30396.pdf. Acesso em: 09 nov. 2018.

BUTLER, J. Corpos que pesam: sobre os limites discursivos do "sexo". In: LOURO, Guacira Lopes (Org.). O corpo educado: pedagogias da sexualidade. Belo Horizonte: Autêntica, 2001. p. 153-172.

BUTLER, J. Problemas de gênero: feminismo e subversão da realidade. Rio de Janeiro: Civilização Brasileira, 2003.

BUTLER, J. Condição humana contra "natureza". Diálogo com Adriana Cavarero. Revista Estudos Feministas. vol.15, n.3, p. 650-662, 2007. Disponível em: http://www.redalyc.org/pdf/381/38115309.pdf. Acesso em: 09 nov. 2018.

BUTLER, J. Conversando sobre psicanálise: entrevista com Judith Butler. Entrevista concedida a Patrícia Porchat Pereira da Silva Kunudsen. Revista Estudos Feministas. vol.18, n.1, p. 161-170, 2010. Disponível em: http://www.scielo.br/pdf/ref/v18n1/v18n1a09.pdf. Acessado em: 09 nov. 2018.

COSTA, E. A. da. Mobilidade e fronteira: as territorialidades dos jovens de Corumbá, Brasil. Revista Transporte y Territorio/9, p. 65-86, 2013. Disponível em: http://revistascientificas.filo.uba.ar/index.php/rtt/ article/view/304/282. Acesso em: 09 nov. 2018.

DUQUE, T. “Lá não tem gay”: fronteira e relações de vizinhança envolvendo gêneros dissidentes e sexualidades disparatadas em Corumbá (MS). $M N E M E$, v. 18, p. 111-124, 2017. Disponível em: https://periodicos. ufrn.br/mneme/article/view/12275/9335. Acesso em: 18 jul. 2018a.

DUQUE, T. Não toque em mim na segunda-feira: diferença, abjeção e identidade em um projeto de extensão no Campus Pantanal da Universidade Federal de Mato Grosso do Sul. Reflexão e Ação, v. 25, p. 22-37, 2017. Disponível em: https://online.unisc.br/seer/index. $\mathrm{php} / \mathrm{reflex} / \mathrm{article} / \mathrm{view} / 7858 / \mathrm{pdf}$. Acesso em: 18 jul. 2018b.

ESSElin, P. M.; OliverA, T. C. M. de; OliveirA, M. A. M. de. Fronteiras Esquecidas: a construção de hegemonia nas fronteiras entre os rios Paraguai e Paraná. Dourados: Ed. UFGD, 2012.

FERNANDES, S. F. As trajetórias de de "jovens trans" na fronteira Brasil/ Bolívia: (in)visibilidade nas escolas públicas de Corumbá (MS). 2018. Dissertação (Mestrado em Educação) - Universidade Federal de Mato Grosso do Sul 
FOUCAULT, M. História da sexualidade: A vontade de saber. Rio de Janeiro, Edições Graal, 2007.

IBGE. Mapa de Biomas do Brasil. Rio de Janeiro, 2002.

KLANOVICZ, Luciana Rosar Fornazari. De Gabriela a Juma: imagens eróticas femininas nas telenovelas brasileiras. Revista Estudos Feministas, Florianópolis, v.18, n.1, p. 141-160, Apr. 2010. Disponível em: http://www.scielo.br/scielo.php?script=sci_arttext\&pid=S0104026X2010000100008\&lng=en\&nrm=iso. Acesso em: 10 fev. 2019

LAMOSO, L. P. Reflexões sobre Corumbá-MS do início do século XXI. In: MORETTI, E. C.; BANDUCCI JUNIOR, A. (Orgs). Pantanal: territorialidades, culturas e diversidade. Campo Grande, MS: Ed. UFMS, 2012. p. 141-171.

MINOIS, G. História do Riso e do Escárnio. São Paulo: Editora da UNESP, 2003.

MISKOLCI, R. Negociando visibilidades: segredo e desejo em relações homoeróticas masculinas criadas por mídias digitais. Bagoas, vol.8, no11, p.51-78, 2014. Disponível em: https://periodicos.ufrn.br/ bagoas/article/view/6543/5073. Acesso em: 09 nov. 2018.

MOTA, M. P.; DUQUE, T. Corpo e questões de gênero e sexualidade nas atividades circenses em uma escola de Corumbá-MS, Brasil. Educação On-line (PUCRJ), v. 13, p. 39-59, 2018.

NEVES, A. A.; FERRAZ, C. B. O. Cinema no Pantanal: construindo uma paisagem a partir das imagens. In: MORETTI, E. C.; BANDUCCI JUNIOR, A. (Orgs). Pantanal: territorialidades, culturas e diversidade. Campo Grande, MS: Ed. UFMS, 2012. p. 173-199.

OCTAVIO, I. A questão nacional na América Latina. Estudos Avançados, vol. 2, n 2, São Paulo, p. 5-40, 1988. Disponível em: http://www. revistas.usp.br/eav/article/view/8474/10025. Acesso em: 18 jul. 2018.

OLIVEIRA, M. A. M; CAMPOS, D. L. Migrantes e Fronteira: lógicas subvertidas, vidas refeitas. In: PEREIRA, J. H. do V. e OLIVERIA, M. A. M. (ORGs). Migração e Integração - resultados de pesquisa em Mato Grosso do Sul. Dourados Ed UFGD, 2012. p. 17-37.

PASSAMANI, G. R. Batalha de Confete: envelhecimento, condutas homossexuais e regime de visibilidade no pantanal-MS. Rio de Janeiro: Papéis Selvagens, 2018.

PASSAMANI, G. R; DUQUE, T. As bichas de hoje e de “ontem” da região do Pantanal de Mato Grosso do Sul: sobre regimes de visibilidade e 
(des) caminhos do curso da vida. In: BRAZ, C. A. de; HENNING, C. E. (Orgs.). Gênero, sexualidade e curso da vida: diálogos latinoamericanos. 01ed.Goiânia: Editora da Imprensa Universitária, 2017, v. 02 , p. 65-92.

PELÚCIO, L. Subalterno quem, cara pálida? Apontamentos às margens sobre pós- -colonialismos, feminismos e estudos queer. ContemporâneaRevista de Sociologia da UFSCar. São Carlos, v. 2, n. 2, p. 395-418, 2012. Disponível em: http://www.contemporanea.ufscar.br/index. php/contemporanea/article/viewFile/89/54. Acesso em: 09 nov. 2018.

PEREIRA, P. P. Queer nos trópicos. Contemporânea - Revista de Sociologia da UFSCar. São Carlos, v. 2, n. 2, p. 371-394, 2012. Disponível em: ttp://www.contemporanea.ufscar.br/index.php/contemporanea/ article/view/88/53. Acessado em: 09 nov. 2018.

PISCITELLI, A. Internseccionalidades, categorias de articulação e experiências de migrantes brasileiras. Sociedade e Cultura. vol.11, n. 2, p. 263-274, 2008. Disponível em: https://www.revistas.ufg.br/ fchf/article/viewFile/5247/4295. Acesso em: 09 nov. 2018.

POSSENTI, S. Os humores da língua: análise linguística de piadas. Campinas, SP: Mercado das Letras, 1998.

PRECIADO, B. Manifesto contra-seuxal. Madri, Opera Prima, 2002.

PRECIADO, B. Texto Junkie: sexo, drogas e biopolítica na era farmacopornográfica. São Paulo: n-1 edições, 2018.

RIBEIRO, M. A. Entre cheias e vazantes: a produção de geografias no Pantanal. Campo Grande, MS: Ed. UFMS, 2015.

SILVEIRA, B. F. S.; DUQUE, T. Gênero, sexualidade e artefato cultural na prisão: um relato de experiência sobre o Projeto ALMA em Corumbá (MS). Instrumento - Revista em Estudo e Pesquisa em Educação, v. 20, p. 75-85, 2018. Disponível em: https://periodicos.ufjf.br/index. php/revistainstrumento/article/view/19108/0. Acesso em: 18 jul. 2018.

SÜSSEKIND, F. O rastro da onça: etnografia de um projeto de conservação em fazendas de gado no Pantanal Sul. 2010. 339 p. Tese. (Doutorado em Antropologia) Museu nacional, Universidade Federal do Rio de Janeiro, Programa de Pós Graduação em Antropologia Social, Rio de Janeiro, 2010.

VENCATO, A. P. Confusões e estereótipos: o ocultamento de diferenças na ênfase de semelhanças entre transgêneros. Homossexualidade, sociedade, movimento e lutas. Campinas: UNICAMP/IFCH/AEL, v.10, n.18, p. 151-179, 2003. Disponível em: https://www.ifch.unicamp. br/ojs/index.php/ael/article/view/2513/1923. Acesso em: 09 nov. 2018. 